\title{
Total lymphocyte count as a surrogate marker for CD4 count in resource-limited settings
}

\author{
Christian Obirikorang $^{1 *}$, Lawrence Quaye ${ }^{2}$ and Isaac Acheampong ${ }^{3}$
}

\begin{abstract}
Background: CD4 testing is the recognized gold standard used to stage HIV/AIDS, guide treatment decisions for HIV-infected persons and evaluate effectiveness of therapy. The need for a less expensive surrogate marker that can be used in resource-limited setting is however necessary. The study sought to assess the suitability of Total lymphocyte count (TLC) as a surrogate marker for CD4 count in resource-limited localities in Ghana.

Methods: This observational study was conducted at the Central Regional Hospital, which has one of the established antiretroviral therapy centres in Ghana. A total of one hundred and eighty-four (184) confirmed HIV I seropositive subjects were included in the study. Blood samples were taken from all the subjects for estimation of CD4 and total lymphocyte counts. The study subjects were further categorised into three (3) groups according to the Centers for Disease Control and Prevention (CDC) classification criteria as follows: CD4 counts (1) $\geq 500$ cells/ $\mathrm{mm}^{3}$ (2) 200-499 cells $/ \mathrm{mm}^{3}$ and (3) $<200$ cells $/ \mathrm{mm}^{3}$. Positive predictive value (PPV), negative predictive value (NPV), sensitivity and specificity of various TLC cut-offs were computed for three groups. Correlation and Receiver Operator Characteristic analysis was performed for the various CD4 counts and their corresponding Total Lymphocyte count obtained.
\end{abstract}

Results: The sensitivity, specificity, positive and negative predictive values of TLC 1200 cells/ $\mathrm{mm}^{3}$ to predict CD4 count were $<200$ cells $/ \mathrm{mm}^{3} 72.2 \%, 100 \%, 100 \%$ and $95.7 \%$ respectively. A TLC of 1500 cells/ $\mathrm{mm}^{3}$ was found to have maximal sensitivity (96.67\%), specificity (100\%), PPV (100\%) and NPV (75.0\%) for predicting a CD4 cell count of 200-499 cell/ $/ \mathrm{mm}^{3}$. A TLC of 1900 cells $/ \mathrm{mm}^{3}$ was also found to have a maximal sensitivity (98.45\%), specificity (100\%), PPV (100\%) and NPV (100\%) for predicting CD4 count $\geq 500$ cells $/ \mathrm{mm}^{3}$. A positive correlation was noted between 184 paired CD4 and TLC counts $(r=0.5728)$.

Conclusion: Total Lymphocyte count can therefore adequately serve as a surrogate marker for CD4 count in HIV patients who are naive for antiretroviral therapy in resource-limited areas.

Keywords: Total lymphocyte count, CD4 count, Sensitivity, Specificity, Human immunodeficiency virus

\section{Background}

Worldwide estimates of people living with Human Immunodeficiency Virus was approximately 32 million in 2007 with thousands of people getting infected every day [1]. Most people living with HIV are from developing countries with less than $5 \%$ receiving antiretroviral therapy [2]. In 2009, an estimated 2.6 million people became infected out of which approximately 1.8 million were from sub-Saharan

\footnotetext{
*Correspondence: krisobiri@yahoo.com

'Department of Molecular Medicine, School of Medical Sciences, College of Health Sciences, Kwame Nkrumah University of Science and Technology (KNUST), Kumasi, Ghana

Full list of author information is available at the end of the article
}

Africa [2]. The initiation of antiretroviral therapy is based on CD4 counts of less than 350 cells $/ \mathrm{mm}^{3}$ according to the World Health Organization (WHO) and Centre for Disease Control (CDC). The determination of CD4 count however in resource-limited localities is difficult. A total lymphocyte count (TLC) of $<1200$ cells $/ \mathrm{mm}^{3}$ has been recommended in addition to WHO staging (stage II) of the disease, for the initiation of antiretroviral therapy in such localities [3]. The use of absolute lymphocyte count as a marker for HIV progression has been argued in many quarters over the years [4-7]. Studies have suggested that when the absolute lymphocyte count is used in conjunction with blood hemoglobin, it gives a more sensitive

\section{Biomed Central}


marker for HIV progression $[6,8]$ with other studies discrediting the use of TLC in such settings $[9,10]$.

The above disagreements in various study settings necessitated the need for this study to be carried out. The aim of this study was therefore to ascertain existing relationships between CD4 count and TLC and to further ascertain if TLC could be used as a surrogate marker for CD4 counts in the initiation of antiretroviral therapy in resource-limited localities in Ghana.

\section{Methods}

This observational study was conducted at the Central Regional Hospital which is one of the established centres providing anti-retroviral therapy (ART) and located at Cape Coast, the capital of the Central region of Ghana. The study was conducted between August 2007 and May 2008. Blood samples were taken from the subjects before the initiation of ART. This study was approved by the Committee on Human Research, Publications and Ethics (CHRPE), School of Medical Sciences, Kwame Nkrumah University of Science \& Technology (KNUST), Kumasi. All patients enrolling in the study completed a written informed consent form in accordance with the Helsinki Declaration. After obtaining consent, demographic questionnaires were completed.

\section{Total lymphocyte count and CD4 cell count}

Blood (5 ml) was drawn into Vacutainer tubes with Ethylenediaminetetraacetic acid (EDTA) and used to determine CD4 cell count and TLC. Samples from the patients were analysed within 2 to 4 hours of collection. TLC was determined by using an automated blood analyzer (CELL-DYN 1800, Abbott Laboratories Diagnostics Division, USA) and CD4 T lymphocytes count was determined using the Becton Dickinson (BD) FASCount system (Becton, Dickinson and Company, Califonia, USA). The BD FASCount system used flow cytometry for the quantification of the CD4 T Lymphocytes.

\section{Subjects}

A total of one hundred and eighty-four (184) HIV I seropositive subjects who were determined by rapid immunochromatographic HIV test kit First Response HIV 1-2 and confirmed with an enzyme-linked immunosorbent assay were included in the study after giving informed consent. The study subjects were categorised into three (3) groups according to the Centers for Disease Control and Prevention Criteria $(\mathrm{CDC})$ classification system that emphasizes the importance of $\mathrm{CD} 4+\mathrm{T}$ lymphocyte testing in clinical management of HIV-infected persons. The groups are: CD4 counts (1) $\geq 500$ cells $/ \mathrm{mm}^{3}$; (2) $200-499$ cells $/ \mathrm{mm}^{3}$; and (3) $<200$ cells $/ \mathrm{mm}^{3}$. Inclusion criteria were at least 18 years of age and HIV-1 seropositivity. Exclusion criteria were antiretroviral therapy and co-morbidity with other medical conditions (e.g. tuberculosis, endocarditis and acute viral infections) which could greatly modify haematologic parameters.

\section{Statistical analysis}

The results were given as mean \pm Standard error of mean (SEM). Correlations were evaluated using the Pearson's correlation test. Sensitivity, specificity, positive and negative predictive values with $95 \%$ confidence intervals (CIs) of various cut-off points of the TLC to predict $\mathrm{CD} 4^{+} \mathrm{T}$ cell count $\geq 500$ cells $/ \mathrm{mm}^{3}, \quad 200-499$ cells $/ \mathrm{mm}^{3}$ and $<200$ cells $/ \mathrm{mm}^{3}$ were calculated. For all statistical comparisons, the level of significance was set at $p<0.05$. Data were analyzed using GraphPad Prism for Windows version 4.02 (GraphPad Software, San Diego, CA, USA).

\section{Results}

The demographic characteristics of the subjects are shown in Table 1. Table 1 shows the means of the ages, CD4 count and TLC of the three groups and these values as expressed as means \pm Standard error of the Mean (SEM). Various TLC cut-off, sensitivity, specificity, positive and negative predictive values for the three CD4 groups are shown in Tables 2. Considering the best cut-off values of TLC, that are with the highest sensitivity and specificity combinations, a TLC of 1200 cells $/ \mathrm{mm}^{3}$ was found to have maximal sensitivity of $72.2 \%$ and specificity of $100 \%$ for predicting a CD4 cell count of $<200$ cells $/ \mathrm{mm}^{3}$. The best TLC cut-off for predicting CD4 count between $200-499$ cells $/ \mathrm{mm}^{3}$ with a maximal sensitivity of $96.67 \%$ and specificity of $100 \%$ was 1500 cells $/ \mathrm{mm}^{3}$ and CD4 count $\geq 500$ cells $/ \mathrm{mm}^{3}$ with maximal sensitivity of $98.45 \%$ and specificity of $100 \%$ was 1900 cells $/ \mathrm{mm}^{3}$ as shown in Table 2. Figure 1 shows the ROC curve for the different groups of CD4 counts. The various areas under the curves for the various CD4 groups (AUC) are also shown in Figure 1. The AUC of the various groups were high (closer to 1 ) making TLC a perfect substitute for CD4 count. A positive Pearson's correlation coefficient $(\mathrm{r})$ of $0.5728(p<0.0001)$ was realised when TLC and CD4 count of the whole group was analysed as shown in Figure 2. A positive correlation $(\mathrm{r}=0.7220, \mathrm{p}<0.0001)$ was demonstrated between TLC and $\mathrm{CD} 4$ count for the group with $\mathrm{CD} 4$ count $<200$ cells $/ \mathrm{mm}^{3}$. A positive correlation of $(\mathrm{r}=0.4106$, $\mathrm{p}=0.056)$ and $(\mathrm{r}=0.480, \mathrm{p}=0.006)$ was also demonstrated for the groups with CD4 between $200-499$ cells $/ \mathrm{mm}^{3}$ and $>500$ cells $/ \mathrm{mm}^{3}$ respectively.

\section{Discussion}

Depletion of lymphocytes, primarily of the CD4 cell subset subsequent to cellular CD4 immunodeficiency has been noted as the hallmark of HIV infection [11,12] and CD4 count has been established as the gold standard for staging 
Table 1 General demographic characteristic of the studied population

\begin{tabular}{llll}
\hline & \multicolumn{3}{c}{ CD4 count (cells/mm $\mathbf{3})$} \\
\cline { 2 - 4 } & $<\mathbf{2 0 0}$ & $\mathbf{2 0 0 - 4 9 9}$ & $\geq \mathbf{5 0 0}$ \\
\hline Age (years) & $37.00 \pm 1.61$ & $34.71 \pm 1.18$ & $32.79 \pm 1.10$ \\
Number of subjects & $71(38.59 \%)$ & $60(32.61 \%)$ & $53(28.80 \%)$ \\
Sex & & & \\
Male & $31(43.67 \%)$ & $23(38.33 \%)$ & $19(35.85 \%)$ \\
Female & $40(56.33 \%)$ & $37(61.67 \%)$ & $34(64.15 \%)$ \\
CD4 (cells $/ \mathbf{m m}^{\mathbf{3}}$ ) & $95.95 \pm 8.96$ & $325.5 \pm 13.26$ & $812.5 \pm 47.86$ \\
TLC (cells $/ \mathbf{m m}^{\mathbf{3}}$ ) & $1018 \pm 105.80$ & $1896 \pm 109.00$ & $2292 \pm 125.4$ \\
\hline
\end{tabular}

The values are expressed as mean \pm SEM.

HIV/AIDS, guiding treatment decisions for HIV-infected persons and evaluate effectiveness of therapy. Establishing a cut-off value for TLC so as to be used as surrogate marker for CD4 in staging, monitoring and as a guide to treatment decisions in HIV infected persons in resource-limited settings has been argued [10]. But in areas where viral loads and $\mathrm{CD} 4$ counts are absent, using the current $\mathrm{WHO}$ guidelines which propose the use of TLC in conjunction with clinical data as a criterion for the initiation of ART is the next option [10]. Threshold analysis was done in this study to find the ability of TLC to predict CD4 counts at three different levels thus $\mathrm{CD} 4<200$ cells $/ \mathrm{mm}^{3}, \mathrm{CD} 4$ between 200-499 cells $/ \mathrm{mm}^{3}$ and CD $4 \geq 500$ cells $/ \mathrm{mm}^{3}$.

The study found that a TLC of 1200 cells $/ \mathrm{mm}^{3}$ had a maximal sensitivity of $72.2 \%$ and a specificity of $100 \%$ for a CD4 count $<200$ cells $/ \mathrm{mm}^{3}$ with a PPV of $100 \%$ and NPV of $95.7 \%$. These maximal sensitivity, specificity, PPV and NPV obtained at this threshold from this study shows a strong relationship between $\mathrm{CD} 4<200$ cells $/ \mathrm{mm}^{3}$ and TLC, making the use of TLC as a surrogate marker in remote and deprived areas of Ghana where there is scarcity of laboratory technologies (i.e. CD4 equipment not available) a good choice. Total lymphocyte count at a cut-off of 1200 cells $/ \mathrm{mm}^{3}$ is a good substitute for $\mathrm{CD} 4<200 \mathrm{cell} / \mathrm{mm}^{3}$ in remote and deprived areas of Ghana: thus 3 in 4 individuals would be given the needed medication if a total lymphocyte count of 1200 cells $/ \mathrm{mm}^{3}$ were used, as recommended by the WHO. This finding is consistent with other reports $[5,6,13,14]$. Spacek et al [6], found sensitivity and specificity of $70.7 \%$ and $81.7 \%$ with Badri \& Wood [13] also finding a sensitivity of $83.4 \%$ and a specificity of $87.3 \%$. Kumarasamy et al [5] also had similar sensitivity and specificity of $73 \%$ and $88 \%$ respectively.

However there have been conflicting results that has been reported $[10,15,16]$. These reports found low sensitivity and specificity between CD4 count and TLC and therefore suggested that TLC could not be used as a surrogate marker.

Daka \& Loha [10] found the sensitivity, specificity, positive and negative predictive values of TLC $<1200$ cells $/ \mathrm{mm}^{3}$ to predict CD4 count $<200$ cells $/ \mathrm{mm}^{3}$ to be $41 \%, 83.5 \%, 87.9 \%$ and $32.5 \%$, respectively. Findings of such studies are obviously conflicting in different countries. These differences could be due to different ethnic, racial, epidemiological and socioeconomic factors [17].

The study was also able to establish different cutoff of TLC for those with CD4 between 200-499 cells $/ \mathrm{mm}^{3}$ and those with CD4 count $\geq 500$ cells/ $\mathrm{mm}^{3}$. The maximal cut-off for those with CD4 between 200-499 cells $/ \mathrm{mm}^{3}$ was 1500 cells $/ \mathrm{mm}^{3}$ and that of those with $\mathrm{CD} 4$ count $\geq 500$ cells $/ \mathrm{mm}^{3}$ was

Table 2 Sensitivity, Specificity, Positive and Negative predictive values of Total lymphocyte count cut-off for various CD4 groups

\begin{tabular}{lccccccc}
\hline & $\begin{array}{c}\text { TLC cut-off } \\
\text { (cells/mm3) }\end{array}$ & Sensitivity (\%) & 95\% Cl & Specificity (\%) & 95\% Cl & PPV (\%) & NPV (\%) \\
\hline & 1000 & 72.22 & 46.52 to 90.31 & 94.44 & 72.71 to 99.86 & 100 & 91.7 \\
CD4 count $<\mathbf{2 0 0}$ & $\mathbf{1 2 0 0}$ & $\mathbf{7 2 . 2 2}$ & $\mathbf{4 6 . 5 2}$ to $\mathbf{9 0 . 3 1}$ & $\mathbf{1 0 0}$ & $\mathbf{8 1 . 4 7}$ to $\mathbf{1 0 0 . 0}$ & $\mathbf{1 0 0}$ & $\mathbf{9 5 . 7}$ \\
(cells/mm $\mathbf{3}$ ) & 1400 & 66.67 & 40.99 to 86.66 & 100 & 81.47 to 100.0 & 77.8 & 94.1 \\
& 1600 & 55.56 & 30.76 to 78.47 & 100 & 81.47 to 100.0 & 65.6 & 91.7 \\
\hline & 1000 & 100 & 88.4 to 100 & 66.67 & 9.4 to 99.2 & 96.8 & 100 \\
CD4 count $\mathbf{2 0 0 - 4 9 9}$ & 1200 & 100 & 88.4 to 101 & 67.67 & 9.4 to 99.3 & 96.7 & 66.7 \\
(cells/mm $\mathbf{3}$ ) & $\mathbf{1 5 0 0}$ & $\mathbf{9 6 . 6 7}$ & $\mathbf{8 2 . 8}$ to $\mathbf{9 9 . 9}$ & $\mathbf{1 0 0}$ & $\mathbf{2 9 . 2}$ to $\mathbf{1 0 0}$ & $\mathbf{1 0 0}$ & $\mathbf{7 5 . 0}$ \\
& 1600 & 93.33 & 77.9 to 99.2 & 100 & 29.2 to 101 & 100 & 60.0 \\
\hline & 1700 & 95.45 & 77.2 to 99.9 & 63.64 & 30.8 to 89.1 & 84.0 & 87.5 \\
CD4 count $\geq \mathbf{5 0 0}$ & 1750 & 96.45 & 77.2 to 99.10 & 72.73 & 39.0 to 94.0 & 87.5 & 88.9 \\
(cells/mm $\mathbf{3}$ ) & 1800 & 97.45 & 77.2 to 99.11 & 90.91 & 58.7 to 99.8 & 95.5 & 90.9 \\
& $\mathbf{1 9 0 0}$ & $\mathbf{9 8 . 4 5}$ & $\mathbf{7 7 . 2}$ to $\mathbf{9 9 . 1 2}$ & $\mathbf{1 0 0}$ & $\mathbf{7 1 . 5}$ to $\mathbf{1 0 0}$ & $\mathbf{1 0 0}$ & $\mathbf{9 1 . 7}$ \\
\hline
\end{tabular}

TLC-Total lymphocyte count; PPV-Predictive positive value; NPV-Negative predictive value; 95\% Cl- 95\% Confidence interval. 

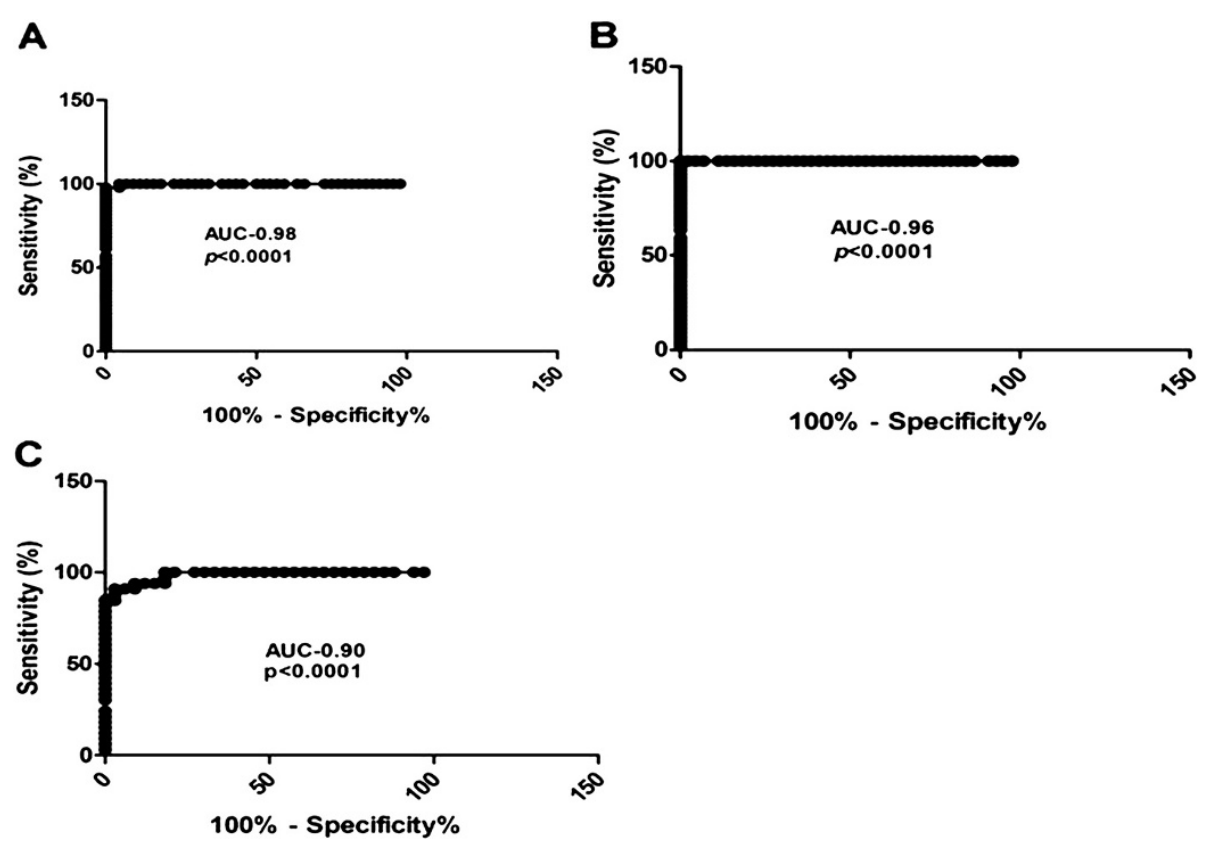

Figure 1 ROC curve for A. CD4 $<200$ cells $/ \mathrm{mm}^{3}$, B. CD4 200-499 cells $/ \mathrm{mm}^{3}$ and C. CD4 $>500$ cells $/ \mathrm{mm}^{3}$.
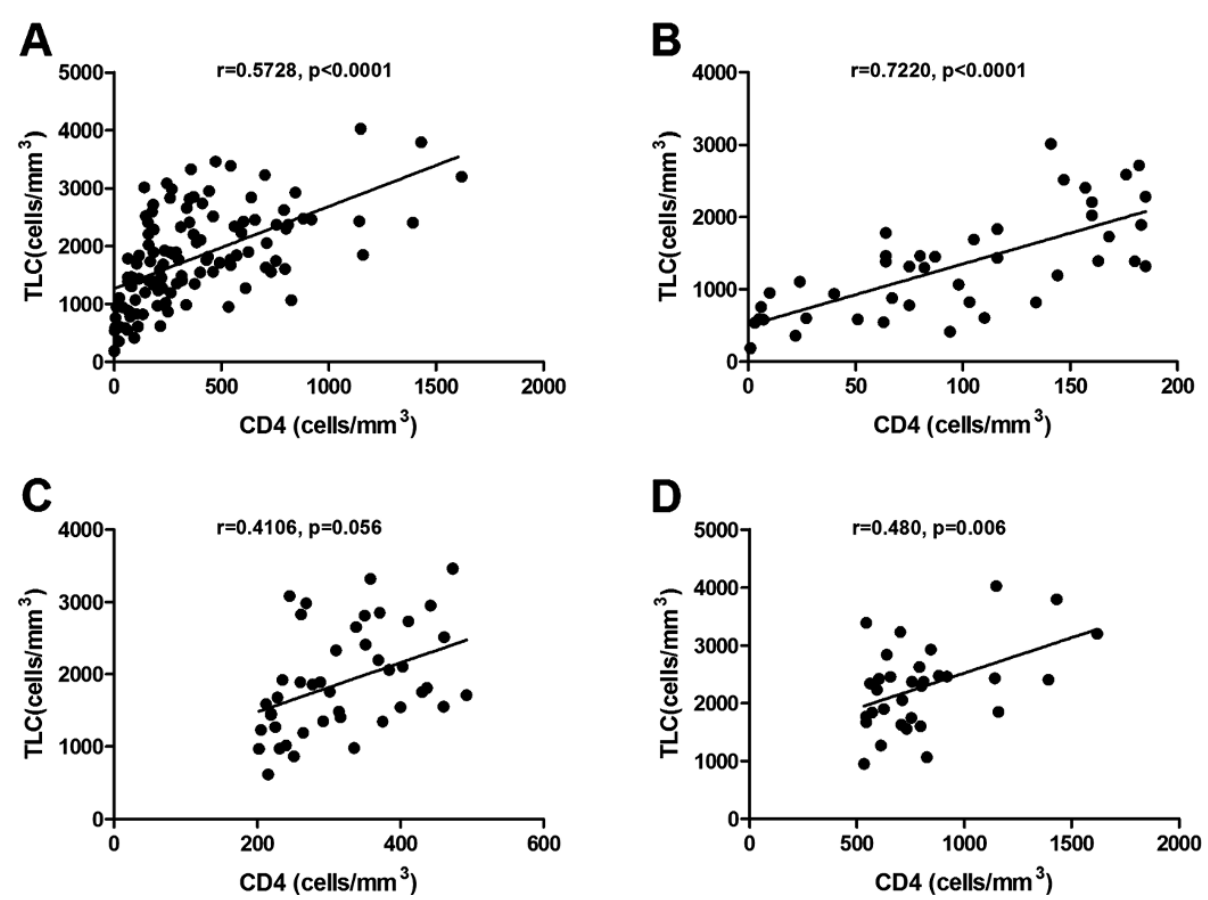

Figure 2 Correlation between Total Lymphocyte Count and (A) the whole group (B) CD4 $<200$ cells $/ \mathrm{mm}^{3}$ (C) CD4 200-499 cells $/ \mathrm{mm}^{3}$ and (D) CD4 $>500$ cells $/ \mathrm{mm}^{3}$. 
1900 cells $/ \mathrm{mm}^{3}$. This can help in taking decisions as to when to initiate ART in resource-limited setting in Ghana where TLC measurement can easily be done.

From the ROC analysis, the AUC were high for those with CD4 count $<200$ cells $/ \mathrm{mm}^{3}, 200-499$ cells $/ \mathrm{mm}^{3}$ and $\geq 500$ cells $/ \mathrm{mm}^{3}$ making the use of TLC a good substitute surrogate marker for CD4 count in resourcelimited settings.

A positive correlation was established between TLC and CD4 count $(r=0.5728, p<0.0001)$ of the whole group. There was even a stronger positive correlation in TLC and CD4 counts of those with CD4 $<200$ cells $/ \mathrm{mm}^{3}$ $(\mathrm{r}=0.7220, p<0.0001)$. Other authors also obtained a stronger correlation between these parameters. These include Jacobson et al [18], who had $r=0.68$; Badri \& Wood [13], who also had $r=0.61$; and Pascale et al [19], who had $\mathrm{r}=0.68$.

\section{Conclusion}

The findings suggest that TLC, which is relatively inexpensive and available, is a reasonably accurate tool that can serve as a surrogate marker in HIV patients who are naive to antiretroviral therapy as to when to initiate antiretroviral therapy in resource-limited settings.

\section{Limitations}

Considering the number of subjects that were enrolled during study period, and the fact that all the subjects were naive for antiretroviral therapy, interpretation of the results obtained should be done with caution.

\section{Competing interests}

We declare that we have no competing interests.

\section{Acknowledgements}

We wish to express our profound gratitude to all PLWHAs who availed themselves voluntarily to participate in this research.

\section{Author details \\ 'Department of Molecular Medicine, School of Medical Sciences, College of Health Sciences, Kwame Nkrumah University of Science and Technology (KNUST), Kumasi, Ghana. ${ }^{2}$ Department of Medical Laboratory Sciences, School of Medicine and Health Sciences, University for Development Studies, Tamale, Ghana. ${ }^{3}$ Laboratory Department, University Hospital, Kwame Nkrumah University of Science and Technology (KNUST), Kumasi, Ghana.}

\section{Authors' contributions}

$\mathrm{CO}$ and IA carried out the TLC and $\mathrm{CD}^{+}$counts, performed the statistical analysis and drafted the manuscript. LQ designed the study and its coordination and participated in the drafting of the manuscript. All authors read and approved the final manuscript.

Received: 27 May 2011 Accepted: 7 June 2012

Published: 7 June 2012

\section{References}

1. UNAIDS/WHO: Joint United Nations Programme on HIV/AIDS, AIDS epidemic update. Geneva, Switzerland: UNAIDS/WHO; 2007.

2. UNAIDS: Report on the Global AIDS Epidemic:: UNAIDS; 2010.

3. WHO: Anti- retroviral therapy for HIV infection in adults and adolescents in resource- limited settings: Towards universal access.: ; 2006.
4. Crowe S, Turnbull S, Oelrichs R, Dunne A: Monitoring of human immunodeficiency virus infection in resource-constrained countries. Clin Infect Dis 2003, 37(Suppl 1):S25-35.

5. Kumarasamy N, Mahajan AP, Flanigan TP, Hemalatha R, Mayer KH, Carpenter CC, Thyagarajan SP, Solomon S: Total lymphocyte count (TLC) is a useful tool for the timing of opportunistic infection prophylaxis in India and other resource-constrained countries. J Acquir Immune Defic Syndr 2002, 31(4):378-383.

6. Spacek LA, Griswold M, Quinn TC, Moore RD: Total lymphocyte count and hemoglobin combined in an algorithm to initiate the use of highly active antiretroviral therapy in resource-limited settings. AIDS 2003, 17(9):1311-1317.

7. van der Ryst E, Kotze M, Joubert G, Steyn M, Pieters $H$, van der Westhuizen $M$, van Staden M, Venter C: Correlation among total lymphocyte count, absolute CD4+ count, and CD4+ percentage in a group of HIV-1-infected South African patients. J Acquir Immune Defic Syndr Hum Retrovirol 1998, 19 (3):238-244.

8. George SJ, Lau B, Phair JP: Use of total lymphocyte count and hemoglobin for staging HIV disease and possibly initiating antiretroviral therapy. Barcelona: XIVth international AIDS conference; 2002 [abstract TuPec4706].

9. Akanmu AS, Akonsete I, Eshoforiee AO, Davies AO, Okanny CC: Absolute lymphocyte count as surrogate for CD4 count in monitoring response to antiretroviral therapy. Niger postgrad Med J 2001 2001, 8:105-111.

10. Daka D, Loha E: Relationship between total lymphocyte count (TLC) and CD4 count among peoples living with HIV, Southern Ethiopia: a retrospective evaluation. AIDS Res Ther 2008, 5:26.

11. Gougeon ML, Montagnier L: Apoptosis in AIDS. Science 1993, 260(5112):1269-1270.

12. Gil L, Martinez G, Gonzalez I, Tarinas A, Alvarez A, Giuliani A, Molina R, Tapanes R, Perez J, Leon OS: Contribution to characterization of oxidative stress in HIV/AIDS patients. Pharmacol Res 2003, 47(3):217-224.

13. Badri M, Wood R: Usefulness of total lymphocyte count in monitoring highly active antiretroviral therapy in resource-limited settings. AIDS 2003, 17(4):541-545.

14. Post FA, Wood R, Maartens G: CD4 and total lymphocyte counts as predictors of HIV disease progression. QJM 1996, 89(7):505-508.

15. Akinola NO, Olasode $O$, Adediran IA, Onayemi $O$, Murainah $A$, Irinoye $O$, Elujoba AA, Durosinmi MA: The search for a predictor of CD4 cell count continues: total lymphocyte count is not a substitute for CD4 cell count in the management of HIV-infected individuals in a resource-limited setting. Clin Infect Dis 2004, 39(4):579-581.

16. Angelo AL, Angelo CD, Torres AJ, Ramos AM, Lima M, Netto EM, Brites $C$ : Evaluating total lymphocyte counts as a substitute for CD4 counts in the follow up of AIDS patients. Braz J Infect Dis 2007, 11(5):466-470.

17. Alavi SM, Ahmadi F, Farhadi M: Correlation between Total Lymphocyte Count, Hemoglobin, Hematocrit and CD4 Count in HIV/AIDS Patients. Acta Medica Iranica 2009, 47(1).

18. Jacobson MA, Liu L, Khayam-Bashi H, Deeks SG, Hecht FM, Kahn J: Absolute or total lymphocyte count as a marker for the CD4 T lymphocyte criterion for initiating antiretroviral therapy. AIDS 2003, 17(6):917-919.

19. Pascale JM, Isaacs MD, Contreras P, Gomez B, Lozano L, Austin E, De Martin MC, Gregory RL, McLaughlin GL, Amador A: Immunological markers of disease progression in patients infected with the human immunodeficiency virus. Clin Diagn Lab Immunol 1997, 4(4):474-477.

doi:10.1186/1471-2334-12-128

Cite this article as: Obirikorang et al:: Total lymphocyte count as a surrogate marker for CD4 count in resource-limited settings. BMC Infectious Diseases 2012 12:128. 